\title{
ANALYSIS OF WEIGHTED SILK
}

\author{
By Ralph T. Mease
}

A generally applicable, rapid, and convenient method for the determination of the amount of pure silk fiber in silk textiles is described. Weighting and finishing materials are removed by repeated extractions with hot water, 2 per cent sodium carbonate solution and a solution containing 2 per cent of hydrochloric and 2 per cent of hydrofluoric acids. Results of analyses of samples of known composition are presented which indicate that the results are correct to within 1 per cent of the weight of the dried finished material. Results obtained by inexperienced analysts working in different laboratories have been in good agreement when samples of the same silk were analyzed. Qualitative methods for the identification of the following weighting materials are given: Aluminum, lead, phosphate, silica, tin, zinc.

\section{CONTENTS}

Page

I. Introduction

669

II. Experimental studies

670

III. A method for the analysis of weighted silk

673

IV. Qualitative tests for inorganic weighting materials

676

\section{INTRODUCTION}

Raw silk, as it comes to the manufacturer, contains about 75 per cent fiber (fibroin) and about 25 per cent gum (sericin) exclusive of moisture. At some stage of the processing the gum is removed by "boiling off" in a soap solution. The silk may then be "weighted" by the addition of various metallic salts or other substances, the amount of the weighting being determined by the purposes for which the silk is intended, the selling price, and similar considerations. The amount of weighting added seldom is less than the amount of the gum removed and it may exceed the amount of the silk fibroin. The claim is made that weighted silk has a better "hand" or "feel" than unweighted silk, that it drapes better, and that its lower cost makes possible the use of silk by persons who otherwise could not afford it.

After weighting, the silk may be dyed, or printed. It is finally "finished" by the addition of gums, soaps, waxes, hygroscopic substances, or other "finishing" materials which contribute to the desired properties.

The need for a standard method of analysis for weighted silk arose several years ago when special attention was being given to the problem of overweighting. There was an insistent demand from numerous manufacturers, distributors, and consumers for definite limits on the amount of weighting to be allowed on different types of silk fabrics. This led to the tentative designation of limits by the Silk Association of America in January, 1929. In order to insure satisfactory analyses of weighted silks for conformance with these standards or other standards that might be agreed upon, attention

1 Fifty-seventh Annual Report, Silk Association of America, New York, p. 27, 1929. 
was given by a Technical Committee on Weighted Silk ${ }^{2}$ to methods of analysis. A proposed standard method was published. ${ }^{3}$

The proposed standard method was the one in common use calling for extraction with hydrofluoric acid, amplified to make possible the successful analysis of silks weighted with materials other than tinphosphate-silicate. When samples of silk of known weighting content were submitted to cooperating laboratories for analysis by this method, the results were in error in one instance by no less than 32 per cent of the amount actually present and in two other instances by 17 and 20 per cent. ${ }^{4}$

In anticipation of the need for analyses of weighted silks in several projects in the textile section of the Bureau of Standards, and with the expectation that the Federal Trade Commission would require analyses of weighted silks, some attention was given to the development of a generally applicable and satisfactory method. This work resulted in a method which is reasonably rapid, convenient, and reliable. The work is described and the resulting method is given in this paper. Qualitative tests that have been found useful in identifying inorganic weighting materials on silk are also given.

\section{EXPERIMENTAL STUDIES}

The important determination in the analysis of weighted silk is that of fibroin content. Several methods have been proposed for obtaining this value. In one method ${ }^{5}$ the fibroin is evaluated by determining nitrogen, which is a constituent of silk fibroin. This value is in error if dyestuffs containing nitrogen are present in the silk. In another method ${ }^{6}$ the fibroin content is indirectly evaluated by making a determination of the ash content of the weighted silk. This is done by igniting a sample in air. The weighting materials are changed during the ignition and the weight of the ash is not a true measure of the weighting materials contained in the material. A third method, which is also indirect, consists in the extraction of inorganic materials with hydrofluoric acid. ${ }^{7}$ When lead, zinc, or aluminum salts are present, however, the material is alternately treated with hydrofluoric and hydrochloric acids. Neither of these last two treatments entirely removes the inorganic materials.

It was found in this laboratory that a solution containing 2 per cent of hydrofluoric and 2 per cent of hydrochloric acids was more effective in removing inorganic weighting materials than either acid alone, or the alternate treatments with these two acids. Furthermore, the combination of hydrofluoric and hydrochloric acids was found to be less destructive to silk fibroin than hydrochloric acid alone.

Unweighted silk cloth was purified by boiling it in several changes of neutral soap solution, then extracting with alcohol to remove soap,

2 The Joint Committee of the Textile Industry on Weighted Silk, composed of representatives from national associations representing manufacturers, distributors, and users, established this smaller technical

3 Anon, To find silk weighting content, Textile World, vol. 76, p. 1454, Sept. 14, 1929.

4 Unpublished data of the Technical Committee on Weighted Silk.

5 Gnehm, R., and Blummer, E., Méthode pour le dosage de la charges des soies noires, Rev. gén. mat. color., vol. 2, pp. 133-134, April, 1898.

B Branegan, James A., Practical analysis of methods for determination of artificial weighting of tin weighted silk, Melliand, vol. 1, pp. 735-739, August, 1929. Compares results obtained with several methods of analysis.

7 Gnehm, R., Eine neue Methode zur quantitativen Bestimmung der Zinn-Phosphat-Silicat-Charge auf Seide, Z. Farben-Textil-Chem., vol. 2, pp. 209-210, June 1, 1903. 
and finally with ether. It was then immersed in boiling water and finally dried in air at room temperature. This silk is referred to as "silk fibroin" in the experiments to be described.

The first step in the analysis of weighted silk by extraction with hydrofluoric acid is the removal of soluble finishing materials; that is, materials soluble in water or organic solvents that might be expected to be removed by either wet washing or dry cleaning. The purpose is not only to obtain a value for the amount of such materials, but to expose the insoluble weighting to more ready attack in subsequent treatments. Rinsing of the specimen with alcohol and ether to complete the removal of soluble finishing materials and to expedite the drying was found to be unsatisfactory because silk fibroin may hold these solvents even when dried above their boiling points. This was demonstrated in the following experiments.

Samples of silk fibroin weighing about $2.5 \mathrm{~g}$ each were dried to constant weight $\left( \pm 0.1\right.$ per cent) in an air oven at $105^{\circ}$ to $110^{\circ} \mathrm{C}$. The time required was 1 to $1 \frac{1}{2}$ hours. Weighings were made at one-half hour intervals up to five hours. These samples were then soaked in 100 times their weight of distilled water at $65^{\circ} \mathrm{C}$. for 20 minutes, rinsed in a fresh portion of distilled water, then in alcohol and finally in ether, a procedure typical of those used for soluble finishing materials. They were then dried to constant weight as before. The dry weight of the samples thus treated was approximately 1.5 per cent more than the weight of the original dry material. The samples were then immersed in boiling water and again dried. After this treatment the samples were found to have returned to their original weight. This procedure was repeated and it was clearly evident that when the silk was rinsed in alcohol and then in ether before drying, the weight of the dry material was considerably higher than when the silk was rinsed finally in boiling water. It was also found by other experiments that the alcohol and ether could be removed by water at temperatures below boiling. On this evidence, the final rinse in alcohol and ether must be followed by immersion of the specimens in water before drying.

After removal of soluble finishing materials, weighting is removed in the hydrofluoric acid method by alternate treatments of the silk with dilute hydrofluoric acid and dilute sodium carbonate solutions. Various concentrations, temperatures, and times of treatment are used in different laboratories. According to the method recommended by the Technical Committee on Weighted Silk, silk weighted with tin phosphate without silicate requires a treatment with dilute hydrochloric acid solution as well as with hydrofluoric acid.

Preliminary experiments indicated that both the concentration and temperature of the reagents are extremely important, too drastic treatment materially affecting the silk fibroin and too mild treatment not removing the weighting completely. Further, a mixture of hydrofluoric and hydrochloric acids ${ }^{8}$ was found to be more efficient and less harmful than the separate treatments with hydrochloric and hydrofluoric acids called for in the method of the technical committee.

The treatments which were finally adopted are described in Section III. The effects of these treatments on silk weighted in several differ-

${ }^{8}$ Suggested informally several years ago by Dr. Victor Froelicher, chief chemist, Textile Dyeing Co. of America. 
ent ways likely to be encountered in practice ${ }^{9}$ are shown in Table 1. The amount of silk fibroin found by analysis of silk of known weighting content agreed with the amount present within 1 per cent of the weight of the dry finished silk for tin phosphate, logwood black, and other types of weighting as well as for the usual tin-phosphate-silicate weighted silk. The average loss in weight of eight samples of silk fibroin, when given the treatment for removing weighting, was 0.49 per cent and the maximum loss was less than 1 per cent.

Analyses of over 75 samples of commercial weighted silks have been made according to the method by several analysts, with excellent results. The amount of dry silk fibroin obtained in duplicate determinations agrees well within 1 per cent of the weight of the dried sample. The ash obtained by igniting the sample after treatment for removal of weighting seldom exceeds 0.1 per cent and is usually very much less than this when the silk is weighted with tin-phosphatesilicate.

Results of a few analyses of commercial samples made independently by analysts of two laboratories using different kind of equipment are given in Table $2 .{ }^{10}$ Evidently good results may be obtained without the use of special equipment.

\section{TABLE 1.-Results of analyses of weighted silks}

[Values are in percentages of the weight of the ovendried specimen. Results of duplicate analyses given]

\begin{tabular}{|c|c|c|c|c|c|c|c|c|}
\hline \multirow[b]{2}{*}{$\begin{array}{c}\text { Sam- } \\
\text { ple } \\
\text { No. }\end{array}$} & \multirow[b]{2}{*}{ Type of weighting } & \multicolumn{4}{|c|}{$\begin{array}{c}\text { Extraction with apparatus of } \\
\text { Figure } 1\end{array}$} & \multicolumn{3}{|c|}{$\begin{array}{l}\text { Extraction with appa- } \\
\text { ratus of Figure } 3\end{array}$} \\
\hline & & $\begin{array}{l}\text { Silk con- } \\
\text { tent }\end{array}$ & $\begin{array}{c}\text { Soluble } \\
\text { finish- } \\
\text { ing ma- } \\
\text { terials }\end{array}$ & $\begin{array}{l}\text { Resid- } \\
\text { ual ash }\end{array}$ & $\begin{array}{c}\text { Silk } \\
\text { fibroin }\end{array}$ & $\begin{array}{l}\text { Soluble } \\
\text { finish- } \\
\text { ing ma- } \\
\text { terials }\end{array}$ & $\begin{array}{l}\text { Resid- } \\
\text { ual ash }\end{array}$ & $\begin{array}{l}\text { Silk } \\
\text { fibroin }\end{array}$ \\
\hline 0 & Tin phosphate & 60.4 & $\left\{\begin{array}{l}4.3 \\
4.5\end{array} \mid\right.$ & 1.2 & $\left\{\begin{array}{l}61.0 \\
60.8\end{array}\right.$ & & & \\
\hline 1 & Tin phosphate silicate.... & 48.3 & $\left\{\begin{array}{l}4.5 \\
3.7\end{array} \mid\right.$ & .0 & $\left\{\begin{array}{l}48.6 \\
49.1\end{array}\right.$ & $\begin{array}{l}3.4 \\
4.2\end{array}$ & 0.5 & $\begin{array}{l}50.2 \\
49.2\end{array}$ \\
\hline 2 & Tin phosphate, lead, silicate & 50.8 & $\begin{array}{l}4.5 \\
5.1\end{array}$ & .8 & $\left\{\begin{array}{l}50.9 \\
50.8\end{array}\right.$ & $\begin{array}{l}4.7 \\
4.6\end{array}$ & .1 & $\begin{array}{l}52.8 \\
52.6\end{array}$ \\
\hline 3 & Tin phosphate logwood black. & 52.1 & $\left\{\begin{array}{l}4.9 \\
5.2\end{array} \mid\right.$ & .1 & $\left\{\begin{array}{l}53.0 \\
53.0\end{array}\right.$ & $\begin{array}{l}2.7 \\
3.4\end{array}$ & .1 & $\left\{\begin{array}{l}55.0 \\
54.3\end{array}\right.$ \\
\hline 4 & Tin phosphate silicate... & 50.1 & $\begin{array}{l}4.7 \\
4.7\end{array}$ & .1 & $\left\{\begin{array}{l}50.5 \\
49.9\end{array}\right.$ & & & -- \\
\hline 5 & Tin phosphate zinc & 60.9 & $\left\{\begin{array}{l}5.2 \\
5.3\end{array}\right.$ & .0 & $\left\{\begin{array}{l}60.6 \\
60.8\end{array}\right.$ & & & \\
\hline 10 & Commercial silk, tin phosphate silicate. & $\begin{array}{l}\text { Un- } \\
\text { known. }\end{array}$ & $\left\{\begin{array}{l}4.8 \\
4.9\end{array}\right.$ & .0 & $\left\{\begin{array}{l}48.4 \\
48.0\end{array}\right.$ & $\begin{array}{l}4.2 \\
3.9\end{array}$ & .0 & $\begin{array}{l}48.1 \\
48.4\end{array}$ \\
\hline 11 & - - do. & $\begin{array}{l}\text { Un- } \\
\text { known. }\end{array}$ & $\left\{\begin{array}{r}6.3 \\
6.0\end{array}\right.$ & .0 & $\left\{\begin{array}{l}50.2 \\
51.0\end{array}\right.$ & $\begin{array}{l}5.8 \\
5.7\end{array}$ & .0 & $\begin{array}{l}50.9 \\
51.1\end{array}$ \\
\hline 12 & ......do & $\begin{array}{l}\text { Un. } \\
\text { known. }\end{array}$ & $\left\{\begin{array}{l}5.2 \\
6.6\end{array}\right.$ & .0 & $\left\{\begin{array}{l}60.0 \\
59.2\end{array}\right.$ & \begin{tabular}{l|l}
4.6 \\
5.2
\end{tabular} & .0 & $\begin{array}{l}59.0 \\
59.0\end{array}$ \\
\hline 13 & - - $_{-} \mathrm{do}$ & $\begin{array}{l}\text { Un- } \\
\text { known. }\end{array}$ & $\left\{\begin{array}{l}6.8 \\
6.5\end{array}\right.$ & .0 & $\left\{\begin{array}{l}92.5 \\
92.3\end{array}\right.$ & $\begin{array}{l}3.4 \\
4.9\end{array}$ & .0 & $\begin{array}{l}93.5 \\
93.1\end{array}$ \\
\hline 14 & ס-- & $\begin{array}{l}\text { Un- } \\
\text { known. }\end{array}$ & $\begin{array}{l}5.5 \\
5.4\end{array}$ & .1 & $\left\{\begin{array}{l}49.1 \\
49.4\end{array}\right.$ & $\begin{array}{l}4.7 \\
5.2\end{array}$ & .1 & $\begin{array}{l}48.3 \\
48.6\end{array}$ \\
\hline 15 & .....do. & $\begin{array}{l}\text { Un- } \\
\text { known. }\end{array}$ & $\left\{\begin{array}{l}5.5 \\
5.2\end{array}\right.$ & .0 & $\left\{\begin{array}{l}42.2 \\
42.3\end{array}\right.$ & $\begin{array}{l}5.3 \\
4.6\end{array}$ & .0 & $\begin{array}{l}41.6 \\
41.2\end{array}$ \\
\hline 16 & -..do. & $\begin{array}{l}\text { Un- } \\
\text { known. }\end{array}$ & $\begin{array}{l}5.4 \\
5.2\end{array}$ & .0 & $\left\{\begin{array}{l}50.5 \\
50.0\end{array}\right.$ & $\begin{array}{l}4.8 \\
5.9\end{array}$ & .1 & $\begin{array}{l}49.6 \\
49.3\end{array}$ \\
\hline 17 & -....do & $\begin{array}{l}\text { Un- } \\
\text { known. }\end{array}$ & $\left\{\begin{array}{l}6.8 \\
6.4\end{array} \mid\right.$ & .0 & $\begin{array}{l}55.2 \\
55.2\end{array}$ & $\begin{array}{l}5.0 \\
5.6\end{array}$ & .1 & $\begin{array}{l}54.9 \\
55.2\end{array}$ \\
\hline
\end{tabular}

- The author is indebted to Dr. Victor Froelicher for the samples of known weighting content representative of the different types of weighting.

${ }_{10}$ These results were obtained under the supervision of Prof. Pauline Beery Mack, of the department of home economics, Pennsylvania State College. 
TABLE 2.-Results of analyses by two independent laboratories on commercial silks

[Values are for silk fibroin expressed as percentages of the weight of the ovendried specimen]

\begin{tabular}{|c|c|c|c|c|c|}
\hline Sample No. & $\begin{array}{l}\text { By Bureau } \\
\text { of Stand- } \\
\text { ards ex- } \\
\text { traction } \\
\text { with ap- } \\
\text { paratus of } \\
\text { Figure } 3\end{array}$ & $\begin{array}{l}\text { By Penn- } \\
\text { sylvania } \\
\text { State Col- } \\
\text { lege labo- } \\
\text { ratory } \\
\text { inex- } \\
\text { perienced } \\
\text { analyst } \\
\text { with no } \\
\text { special } \\
\text { equipment }\end{array}$ & Sample No. & $\begin{array}{l}\text { By Bureau } \\
\text { of Stand- } \\
\text { ards ex- } \\
\text { traction } \\
\text { with ap- } \\
\text { paratus of } \\
\text { Figure } 3\end{array}$ & \begin{tabular}{|} 
By Penn- \\
sylvania \\
State Col- \\
lege labo- \\
ratory \\
inex- \\
perienced \\
analyst \\
with no \\
special \\
equipment
\end{tabular} \\
\hline 41 & $\begin{array}{l}98.8 \\
91.5 \\
62.0 \\
57.7\end{array}$ & $\begin{array}{l}99.3 \\
91.8 \\
61.6 \\
58.3\end{array}$ & $\begin{array}{l}51 \ldots \\
52 \ldots \\
53 \ldots \\
54 \ldots\end{array}$ & $\begin{array}{l}97.2 \\
91.8 \\
65.4 \\
58.2\end{array}$ & $\begin{array}{l}98.3 \\
92.0 \\
67.2 \\
58.9\end{array}$ \\
\hline $\begin{array}{l}45 \\
46 \\
47 \\
48\end{array}$ & $\begin{array}{l}49.4 \\
49.3 \\
47.5 \\
43.8\end{array}$ & $\begin{array}{l}48.7 \\
48.3 \\
46.8 \\
43.3\end{array}$ & $\begin{array}{l}55 \\
56 \\
57 \\
58 \\
-\end{array}$ & $\begin{array}{l}54.8 \\
49.4 \\
48.5 \\
41.4\end{array}$ & $\begin{array}{l}55.6 \\
50.8 \\
50.0 \\
42.9\end{array}$ \\
\hline
\end{tabular}

\section{A METHOD FOR THE ANALYSIS OF WEIGHTED SILK}

The specimen for analysis should be representative of the cloth. A strip the full width of the cloth is suggested and should weigh from 3 to $5 \mathrm{~g}$.

The specimen is dried at $105^{\circ}$ to $110^{\circ} \mathrm{C}$. to constant weight ( \pm 0.1 per cent). If the specimen is loosely spread on a watch glass and placed in the usual laboratory electric oven at $105^{\circ}$ to $110^{\circ} \mathrm{C}$., it should dry within one and one-half hours. It is then placed in a tared weighing bottle, allowed to cool in a desiccator, and weighed. The weight of the dry specimen is called weight A.

Soluble finishing materials are removed by the following treatments. The specimen is immersed for about two minutes each in two $30 \mathrm{ml}$ portions of diethyl ether at room temperature, squeezing by hand after each immersion. Then it is treated similarly with two $30 \mathrm{ml}$ portions of ethyl alcohol at $50^{\circ}$ to $60^{\circ} \mathrm{C}$. Finally it is immersed in 90 to 100 times its weight of distilled water at $65^{\circ}$ to $70^{\circ} \mathrm{C}$. for 20 minutes, squeezed by hand, and rinsed by immersion for about onehalf minute each in three fresh portions of distilled water at the same temperature, squeezing by hand after each immersion. It is then dried at $105^{\circ}$ to $110^{\circ} \mathrm{C}$. as before. The weight of the dry specimen at this stage is called weight $\mathrm{B}$.

Weight $\mathrm{A}$-weight $\mathrm{B} \times 100$ /weight $\mathrm{A}=$ soluble finishing materials in per cent (based on the weight of the dried specimen).

The more firmly held weighting and finishing materials are now removed by the following series of treatments: (a) The specimen is immersed in 90 to 100 times its weight of a solution ${ }^{11}$ containing 2 per cent of hydrofluoric acid and 2 per cent of hydrochloric acid maintained at a temperature of $55^{\circ}$ C. $\pm 1^{\circ}$ C. The acid liquid is decanted and the specimen is rinsed with two portions of distilled water at $55^{\circ}$ to $60^{\circ} \mathrm{C}$. squeezing by hand after each rinse. (b) The

11 This reagent may conveniently be prepared by mixing equal volumes of 4 per cent $( \pm 0.1$ per cent) hydrofluoric and 4 per cent ( \pm 0.1 per cent) hydrochloric acids. High concentrations of mineral acids disintegrate silk. Too low a concentration may not remove inorganic materials sufficiently well from all types of weighted silk fabrics. For this work the concentration of each of the acids was determined by titration of weighted silk fabrics. For this work the concentration of each of the acids was determined by titration
with a standard base. The concentrations given mean per cent by weight of actual $H F$ and $H C l$ (not of the ordinary concentrated acids). The reagent is approximately $N$ with respect to $H F$ and $N / 2$ with respect to $\mathrm{HCl}$. 
treatment with acid solution (fresh solution) followed by rinsing is repeated. (c) This treatment is again repeated using a 2 per cent solution of sodium carbonate in place of the acid solution. ( $d$ and $e$ ) The treatment with acid solution is then applied two times more. $(f)$ The specimen is then rinsed several times with distilled water and is dried as previously described. The dry weight is called weight C. Provided all materials other than silk fibroin have been removed
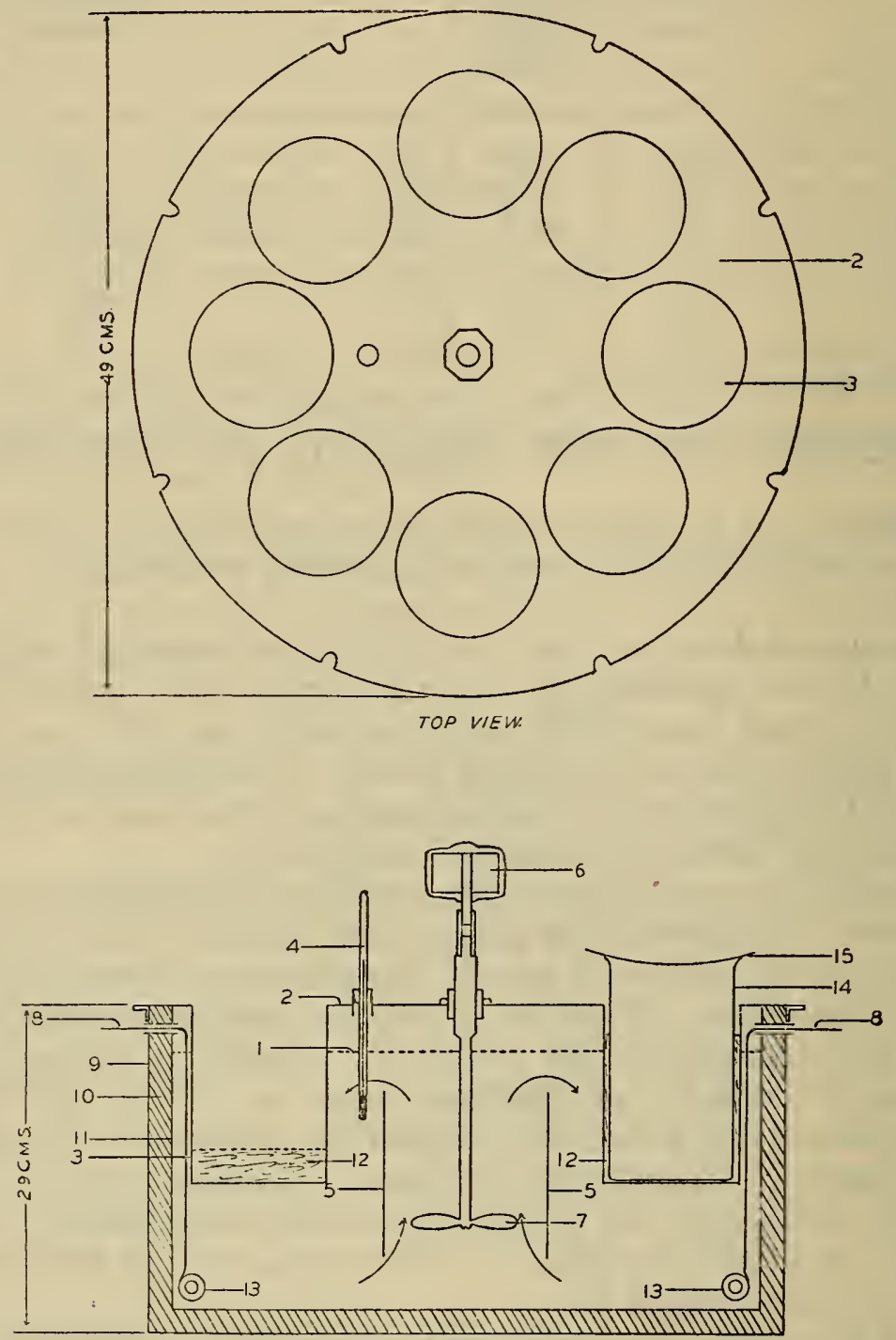

CROSS SECTIONAL VIEW.

Frgure 1.-Electrically heated oil bath for control of the temperature of the solutions during the extraction process

1 , level of oil in the bath; 2 , metal cover; 3 , body of water bath container; 4 , thermorneter; 5 , wall of cylinder to guide the circulating oil; 6 , electric motor; 7 , propeller blade for agitating the oil bath; 8 , glass insulated electric leads to heater coil; 9, outer wall of metal container; 10 mineral wool for heat insulation; 11, inner wall of double-jacketed metal container; 12 , water bath; 13 , nichrome wire heating coil-1 unit of a 3 and 1 of a 4 amp current consumption at $110 \mathrm{v} ; 14,800 \mathrm{ml}$ Pyrex beaker, tall form; and 15, watch glass cover.

(see suggestions for ashing the specimen below), then: Weight $\mathrm{C} \times 100$ /weight $\mathrm{A}=$ silk fibroin in per cent (based on the weight of the dried specimen).

Weight $A$-weight $C \times 100 /$ weight $A=$ total weighting in per cent (based on the weight of the dried specimen). 
The total weighting thus obtained includes all substances other

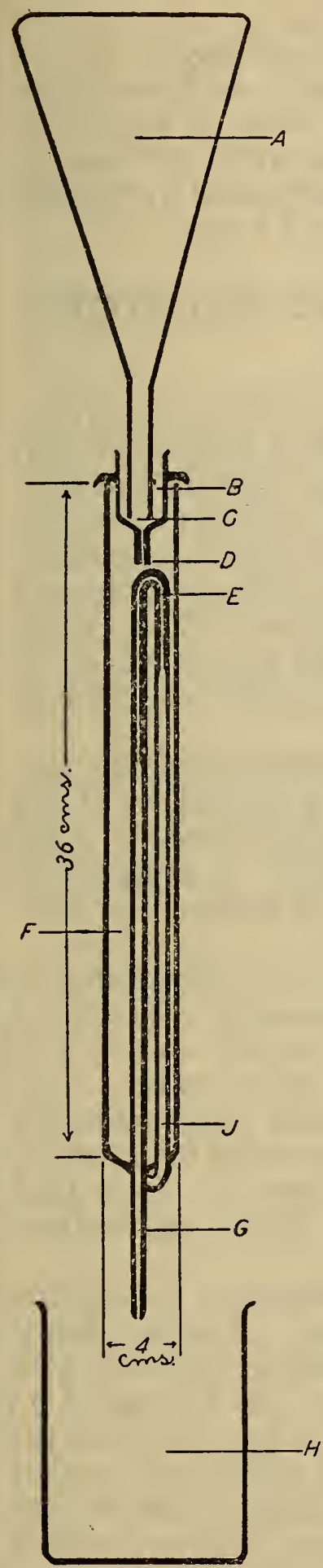

FIgURE 2.-A semiautomatic extraction apparatus for analysis of weighted silk

$A, 1,000 \mathrm{ml}$ Erlenmeyer flask: $B$, trap; $C$, outlet for liquid and inlet for air to flask $A$; $D$, capillary tube controlling flow of liquid; $J E G$, siphon tube; $F$, chamber for samples; and $H$, reservoir for spent liquor.

glass and coated on than silk fibroin.

Weighting is adequately removed from some silks when steps (b) and (e) are omitted, but these steps are necessary for the complete removal of weighting from others. It is advisable to determine the ash as a check on the effectiveness of the extraction. Ashing is done preferably by heating the specimen in a well ventilated muffle furnace. If the weight of the ash is more than 0.2 per cent it should be subtracted from the value obtained for weight $\mathrm{C}$ in the formulas.

The simple oil bath shown in Figure 1 is a convenience if a number of analyses are to be made. With it the temperature of the solutions can readily be controlled to within $1^{\circ} \mathrm{C}$. and eight specimens can be handled simultaneously.

When many samples are to be analyzed time may be saved by using a battery of semiautomatic extraction units. One of these units, constructed of thick walled Pyrex glass, is shown in Figure 2. The specimens to be extracted are placed loosely in the tube, $F$.

Apparatus of the dimensions indicated will hold five specimens. The liquid is placed in the 1-liter flask, heated to the proper temperature, and the flask is inverted in the position shown at $A$. The orifice, $D$, is of such size that 15 to $20 \mathrm{~min}-$ utes are required for the flask to empty. The extraction is not always quite so thorough with this apparatus as when the specimens are treatea individually in beakers in the constant temperature bath.

Concentrated hydrofluoric acid may be measured with a pipette like that shown in Figure 3. Such a pipette may be made of Pyrex the inside by drawing melted ozokerite into the

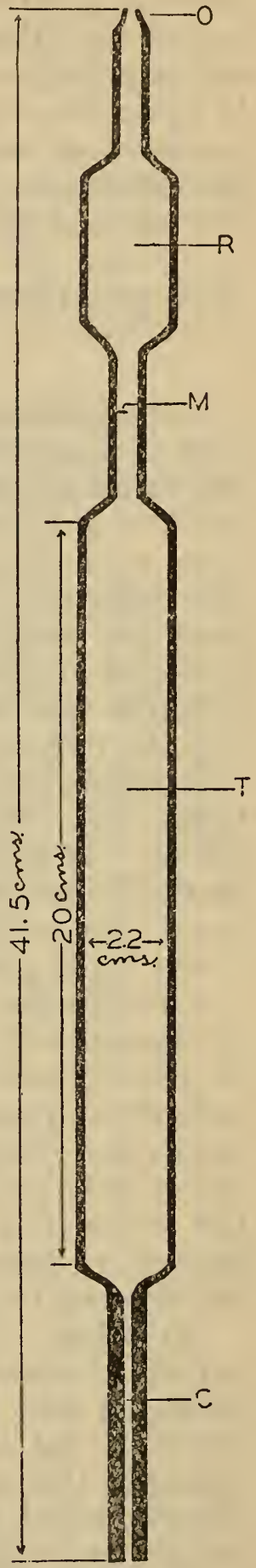

Figure 3.- $A$ pipette for transferring and measuring concentrated hydrofluoric acid

$T$, main reservoir; $R$, auxiliary reservoir; $M$, calibration mark; $O$, suction orifice; and $\mathrm{C}$, capillary discharge tube. 
cold pipette and allowing the excess to drain. The acid is drawn into the pipette by means of a rubber tube attached at one end to $O$ and at the other to the laboratory vacuum. The acid may be diluted and handled in a Pyrex beaker also coated on the inside with ozokerite. If hydrofluoric acid comes in contact with the skin, it should be removed as soon as possible by washing with a solution of borax to prevent burns. Hydrofluoric acid burns should be treated by keeping the affected parts moist with a saturated solution of borax.

\section{QUALITATIVE TESTS FOR INORGANIC WEIGHTING MATERIALS}

The qualitative tests briefly described below provide for the detection of aluminum, lead, phosphate, silicate, tin and zinc when any one or all are present. They are based upon those described in textbooks ${ }^{12}$ of chemical analysis and were chosen for reliability, convenience as to length of time required, and simplicity of manipulation. The tests are useful only for the detection of substances commonly used for weighting according to present practices. When small amounts of these substances are to be detected or additional or interfering ones are suspected of being present, the analyst should consult the references given in footnote 12 .

Detection of inorganic materials in silk.--Inorganic weighting materials are conveniently detected by burning a small piece of the fabric. The ash will retain the form of the original threads if the material has been weighted with inorganic materials. A sample that is not thus weighted will curl back upon itself as it is burned and leave a soft black globular ash.

Identification of inorganic weighting materials-(a) Preparation of the sample.-A piece about 4 by 10 inches is thoroughly wet with a solution containing $90 \mathrm{~g}$ of anhydrous sodium carbonate and $90 \mathrm{~g}$ of anhydrous potassium carbonate, dissolved in $400 \mathrm{ml}$ of water. It is suspended over a beaker containing $30 \mathrm{ml}$ of dilute (approximately 10 per cent) hydrochloric-acid solution and partially dried by brushing the flame of a hand torch or Bunsen burner across it. It is then ignited by directing the flame on the lower edge. The fused portions are allowed to drop into the acid in the beaker.

(b) Silica.-If silicates are present, a white flocculent precipitate is formed when the acid solution from $(a)$ is boiled. The solution is decanted and filtered and the residue in the beaker digested with about $10 \mathrm{ml}$ of warm concentrated hydrochloric acid for about 15 minutes; this acid is poured through the filter paper and added to the filtrate, which is boiled with $5 \mathrm{ml}$ of concentrated nitric acid, cooled neutralized with sodium hydroxide ( 25 per cent solution) and enough hydrochloric acid added to produce a clear solution. The solution is used for tests $(c)$ to $(g)$ described below.

(c) Lead.-About $3 \mathrm{ml}$ of the solution is neutralized with sodium hydroxide using phenolphthalein as an indicator. The solution is then made just acid with hydrochloric acid and about $1 \mathrm{ml}$ of water saturated with hydrogen sulphide is added. If lead is present, a gray

12 Prescott, Albert B., and Johnson, Otis C., Qualitative Chemical Analysis, 7th ed., thoroughly revised. 436 pp., 1916. D. Van Nostrand Co., New York. Scott, Wilfred W., Standard Methods of Chemical Analysis, 4th ed., vol. 1, 745 pp., 1925. 'D. Van Nostrand Co., New York. Hillebrand, W. F., and Lundell, G. E. F., Applied Inorganic Analysis, 929 pp., 1929. John Wiley \& Sons (Inc.), New York 
to black coloration is produced. (A yellow precipitate indicates the presence of tin.) If the sample of silk to be tested is light in color, it may be tested directly for lead by moistening it with water and exposing it to a jet of hydrogen sulphide gas. A change to gray or black indicates the presence of lead.

(d) Aluminum.- To about $3 \mathrm{ml}$ of the solution, $1 / 2 \mathrm{ml}$ of a saturated solution of ammonium chloride, $1 / 2 \mathrm{ml}$ of alizarin (prepared by dissolving $0.1 \mathrm{~g}$ of the dye, Colour Index No. 1034 in distilled water), and an excess of ammonium hydroxide are added. The mixture is heated to boiling, an excess of glacial acetic acid is added, and the mixture diluted. A red flocculent precipitate denotes the presence of aluminum.

(e) Tin.-About $2 \mathrm{ml}$ of the solution is neutralized with 25 per cent sodium hydroxide and about five drops in excess added. The solution is filtered, the filtrate acidified with hydrochloric acid, and a few drops of a 1 per cent water solution of cupferron added. A white precipitate indicates the presence of tin.

(f) Zinc.-About $3 \mathrm{ml}$ of the solution is neutralized with 25 per cent sodium hydroxide, enough hydrochloric acid and water are added to produce a clear solution, and about $1 / 2 \mathrm{ml}$ of a 2 per cent solution of potassium ferrocyanide is then added. A white precipitate indicates the presence of zinc.

(g) Phosphate-About $2 \mathrm{ml}$ of the solution is neutralized with sodium hydroxide and the resulting solution is acidified with nitric acid. It is heated and then added to an equal volume of hot acid ammonium molybdate. A lemon yellow precipitate is formed on standing if phosphates are present.

Washington, July 25, 1932.

$$
\text { 141809-32-7 }
$$

